\title{
Solar Thermal Energy Generation Potential in Gujarat and Tamil Nadu States, India
}

\author{
C. Nagarjuna Reddy*, T. Harinarayana \\ Gujarat Energy Research and Management Institute, Gandhinagar, India \\ Email: "naga2980@outlook.in
}

Received 21 November 2015; accepted 28 December 2015; published 31 December 2015

Copyright (C) 2015 by authors and Scientific Research Publishing Inc.

This work is licensed under the Creative Commons Attribution International License (CC BY).

http://creativecommons.org/licenses/by/4.0/

cc) (i)

Open Access

\begin{abstract}
Government of India has come out with an ambitious target of $100 \mathrm{GW}$ of using solar energy alone by the year 2022. To reach this target, innovative ideas are required to use the solar energy more effectively. For solar electricity generation, mainly two types of technologies are presently in use, namely, solar PV and solar thermal. Being a tropical country, India has large solar PV and solar thermal energy. More research is required on economic aspects to make the solar thermal competitive to solar PV. Towards this direction, in our present study we have simulated a solar thermal power plant using Parabolic Trough Collector (PTC) technology and normalized with 1 MW solar thermal power plant at Gurgaon near New Delhi. Through simulation, we have extended our study and computed the electricity generation possible at different locations of India. For this purpose with $1^{\circ} \times 1^{\circ}$ spacing, computations have been carried out at 296 locations. The work is further extended for more detailed study at two representative states, namely, Gujarat and Tamil Nadu. In these two states, closer data points with $0.25^{\circ} \times 0.25^{\circ}$ spacing have been considered at 273 locations for Gujarat and 197 locations for Tamil Nadu. Our results indicate a large potential of electricity generation using solar thermal energy in southern states of India, namely, Tamil Nadu, Karnataka, Kerala, southern and western part of Andhra Pradesh and eastern part of Maharashtra. Good potential has also been observed in eastern parts of Gujarat and parts of Madhya Pradesh and eastern part of Rajasthan. The annual potential ranges from $1800 \mathrm{MWh}$ to as much as 2600 MWh. Major parts of northern states, for example Uttar Pradesh, Bihar, West Bengal, Punjab, Jammu and Kashmir have medium range potential. Here, the annual potential ranges from 1000 to $1500 \mathrm{MWh}$. Poor range of potential is observed towards eastern parts of India and north eastern states. Here, the electricity generation potential ranges from 600 to $1200 \mathrm{MWh}$. Our results are useful to solar thermal developer and decision managers.
\end{abstract}

\section{Keywords}

Solar Thermal, Parabolic Trough, Energy, India, Gujarat, Tamil Nadu, Modelling

"Corresponding author.

How to cite this paper: Nagarjuna Reddy, C. and Harinarayana, T. (2015) Solar Thermal Energy Generation Potential in Gujarat and Tamil Nadu States, India. Energy and Power Engineering, 7, 591-603. http://dx.doi.org/10.4236/epe.2015.713056 


\section{Introduction}

Water and energy can be considered as two eyes of any nation. If the Government provides or facilitates these two items adequately, the nation grows. It helps the economy to grow. It facilitates the people to live comfortably and happily. Many workers have provided innovative ways and suggested new methodologies for energy security [1]-[5]. Clean water and clean energy make all the people in this world healthy and help to live longer with fewer problems. However, many nations in this world are starving for both clean water and the energy. For example, majority of the islands like Papua New Guinea, Fiji islands, parts of Andaman, Nicobar and Lakshadweep in India are suffering from acute shortage of electricity. At these locations, diesel generators are being used for electricity generation. For this purpose, diesel oil is transported from nearby main land to these islands [6]. In view of this, the cost per unit electricity generation is nearly double as compared to the persons living on the main land.

It is well known that India is facing acute power shortage. The present electrical power generation is close to $250 \mathrm{GW}$. In the estimation, India is expected to generate about $1300 \mathrm{GW}$ by the year 2034 [7]. This is nearly more than 5 times the present generation value. In order to reach this target, all types of fuels need to be used. In present day scenario, coal is being used as a major source for electricity generation in India, as compared to other fuels. Due to increase in demand for more power, sufficient quantity of coal could not be supplied to the thermal plants. For this purpose, we are now importing the coal to reach the power demand. It is well known that coal is not the preferred source of energy due to various issues related to pollution as it omits large $\mathrm{CO}_{2}$ in the atmosphere and creates climate change problem. For all these above reasons, renewable energy is being projected and promoted by majority of the nations around the world.

In this direction, India is ambitiously planning to generate $100 \mathrm{GW}$ of electricity from solar energy alone by the year 2022. We need to have clear roadmap to reach this target from the present generation of nearly $2 \mathrm{GW}$ of installed capacity. There are mainly two types of technologies presently known to generate electricity using solar energy, namely, solar PV and solar thermal. Due to economic considerations, solar PV has become more popular and widely being used as compared to Solar thermal. However if the number of solar developers using Solar thermal technology increases, the cost of Solar thermal technology is likely to be competitive to solar PV. It is reported that among the available solar thermal technology of Parabolic Trough Collector (PTC), Linear Fresnel Reflector (LFR), Solar tower and Dish sterling, Parabolic Trough Collector is more popular and is being used at many locations around the world [8] [9].

Being a tropical country with 300 sunny days, apart from solar PV solar thermal technology, India also needs to be promoted. With more innovations in solar thermal technology and with "Make in India" campaign, cost may be likely to come down and affordable. Ministry of New and Renewable Energy (MNRE), government of India is carefully experimenting the solar thermal technology with pilot scale projects. With its full support, IITBombay has installed $1 \mathrm{MW}$ power plant in Gurgaon. Government of India also supports private players to initiate the electrical generation using solar thermal technology in Rajasthan, Gujarat and also in Andhra Pradesh. In such a scenario, it is of utmost importance to have an estimation of solar thermal potential for the whole country. Presently majority of the solar developers are using the solar irradiation maps. While such maps are necessary and helpful, they are not sufficient. This fact is realized that solar PV potential for India on a regional scale and more detailed maps for Gujarat, Andhra Pradesh and Telangana states has been prepared recently [7]. In a similar manner, it is of great help for the solar developers, if a solar thermal energy generation potential map for India and different states is made available. Towards this direction, an attempt has been made in our present study to estimate the solar thermal potential by simulating the PTC technology similar to the installed solar thermal plant near Delhi. For this purpose, simulation studies have been initiated and results have been compared with the existing power plant of Delhi. With the same initial parameters, computations have been extended to different locations of India. Additionally for Gujarat and Tamil Nadu states are chosen with closer station interval to prepare solar thermal energy generation potential maps for different months and also on annual basis. The methodology followed and results obtained are discussed in the following section.

\section{Methodology}

\subsection{Design of Solar Thermal Power Plant}

The solar thermal power plant installed at Gurgaon near Delhi by IIT Bombay is 1 MW capacity (Figure 1). In 


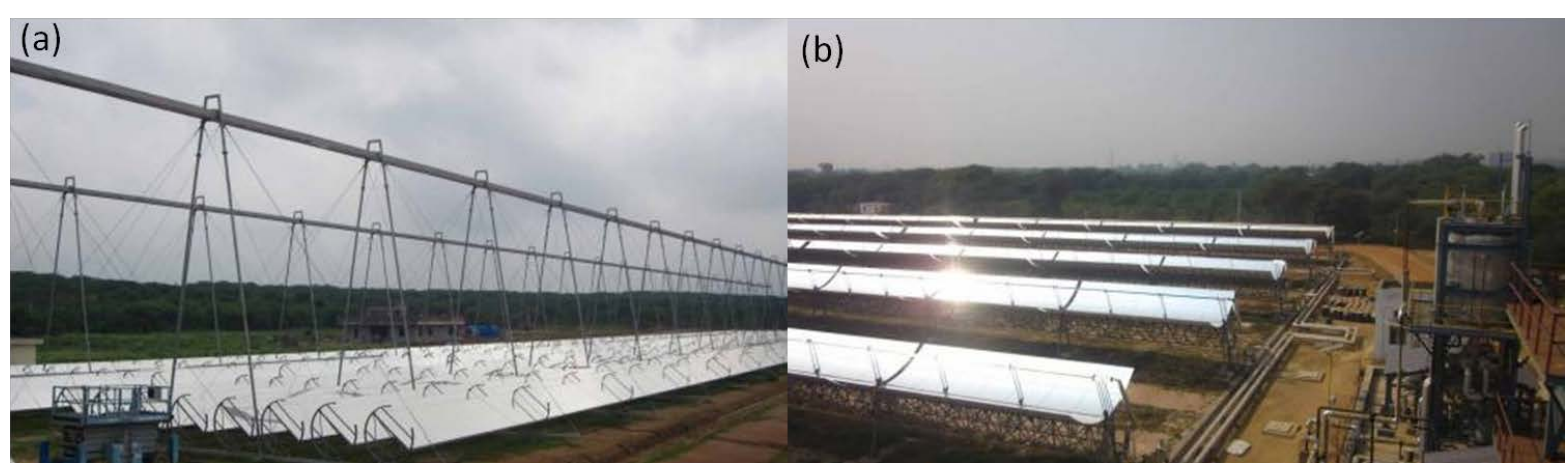

Figure 1. Photo showing the 1 MW solar thermal power plant installed at Gurgaon, New Delhi. The plant uses two types of technologies. The linear Fresnel reflector technology is shown in (a) and the parabolic trough collector technology is present in (b).

this power plant mainly two types of technologies have been used, namely, Linear Fresnel Reflector and Parabolic Trough Collector with therminol VP1 oil as fluid. The plant at Gurgaon has been studied in detail by Desai et al. [10]. In their study, they have simulated both Linear Fresnel field and Parabolic Trough field. The power output for different months except January, July, August and December are provided. In these months, it is reported that due to low DNI values of radiation, the plant remain non-operational. The simplified flow diagram of Gurgaon 1 MW solar thermal power plant can be seen in Figure 1 of Desai et al. (2013).

The Linear Fresnel Reflector (LFR) technology (Figure 1(a)) contains a fixed receiver pipe while mirrors track the solar radiation. These mirrors usually consist of multiple small mirror facets. Each mirror is thin, low weight and low volume lens with short focal length. In parabolic trough collector technology, the mirror shape acts as a parabolic trough to concentrate the direct solar radiation on to a tubular receiver. This technology constitute large share in installed solar thermal power technology. Its share crosses more than $90 \%$ of the capacity as compared to different technologies available in solar thermal power technology that is in operation today. For example the installed capacity of solar power as on 2010 is 821.9 MW. Among this, 93.6\% of the power comes from parabolic trough, while solar tower technology is about 5.1\%, dish sterling technology is $0.2 \%$ and Fresnel technology is 1.1\% [11]. Accordingly in our present study, we have simulated using PTC technology. In our simulation, we have used 3 different softwares, namely, Meteonorm, Surfer and TRNSYS. They are briefly described in the following.

\subsection{Meteonorm Software}

This software gives solar irradiation data for any place on the Earth for a given coordinates. The software systematically organizes the data internally and provides the data in different formats as per the requirement. Based on our requirement, data can be used for solar thermal, solar photo voltaic or building simulation [12]. The meteonorm data are based on 8325 number of weather stations all over the world. For our present requirement of solar thermal plant, we have taken TMY2 data format. This format is compatible to another software-TRNSYS. Firstly, we have defined a location by specifying latitude and longitude. From these two parameters altitude and time zone are updated. We have taken open situation mode for all the locations. From these values, the average climate data of temperature from 2000-2009 and radiation from 1991-2010 are considered. By proceeding further, we can get the weather data for a given location. They are radiation, irradiance, cloud cover fraction, air temperature, humidity, wind direction, wind speed, pressure. These climatic parameters are fed to TRNSYS software to compute solar thermal power generation for a given design of a plant.

\subsection{TRNSYS Software}

TRaNsient SYstem Simulation (TRNSYS) is mainly used to model and simulate energy systems [13]. It is used by engineers and researchers around the world to validate new energy concepts from simple domestic hot water systems to the design and simulation of buildings and their equipment, including control strategies, alternative energy systems-wind, solar photovoltaic, solar thermal, hydrogen systems etc. The library in the software includes many components commonly found in thermal and electrical energy systems. It is developed with many thermal and energy equations that re internally computed for a given design of the power plant. The main win- 
dow is simulation studio. The input parameters are component connections of a solar thermal plant and climatic data. Firstly, we have prepared all the components in the simulation studio of TRNSYS. By using the control card the required number of hours (from 0 hour to 8760 hour-365 days) are given. From this data energy generation for each month is obtained. The values for each month for different locations have been gridded, contoured to generate maps using surfer software.

\subsection{Surfer Software}

Surfer is windows based software and can be used for gridding, blanking, contouring, 3D surface mapping etc, [14]. By taking XYZ data from the user maps can be generated based on the requirement. It is developed mainly with statistical equations with more user friendly as compared to the well known Excel package of MS-Office. Here we have taken $\mathrm{X}$ value as longitude, $\mathrm{Y}$ value as latitude and $\mathrm{Z}$ as the power output from the simulated plant for a specified location. Using these three values the data is subjected to gridding using Krigging method and color filled contouring. Firstly, a base map is prepared and color contour map has been added with uniform grid spacing maintaining in both $\mathrm{X}$ and $\mathrm{Y}$ directions. In our present study, surfer version 11 has been used.

\subsection{Design of Solar Thermal Plant Using TRNSYS}

Based on TRNSYS software, we have designed a simplified power plant (Figure 2) using Parabolic Trough Collector (PTC) technology. This is mainly due to non-availability of LFR technology in the software. For this purpose TRNSYS software Version 17.2.4 [13] has been used and simulated. Another limitation encountered is the magnitude of the power plant. Using TRNSYS software large thermal plants ( $>1 \mathrm{MW})$ can easily be simulated as compared to small plants. Accordingly, we have first computed the power output for a plant with initial input parameters presented in Table 1, using PTC for different months. For this purpose, DNI data obtained from the Meteonorm software [12] for a given location, presently the Gurgaon has been used. In our design PTC, the solar radiation falls on the parabolic trough gets reflected and concentrated on a tube like structure placed near the center of the parabolic trough at a distance. In this tube, the therminol fluid flow in a closed loop. The fluid after getting heated up enters into a high temperature tank. From there, it flows through three chambers, namely super heater, steam generator and preheater. At these three chambers, heat exchanges between the therminol and water. From the preheater, the temperature comes down to about $200^{\circ} \mathrm{C}$. This fluid enters into low temperature tank, from which it enters the tube located in the parabolic trough, thus completing the closed circular movement. As can be seen from the Figure 2, there is another closed loop movement on the right hand side. Water gets pre heated enters into a steam generator and later on to the super heater. In super heater, the temperature of the steam is about $350^{\circ} \mathrm{C}$ and enters into turbine which in turn generates the electricity. From the turbine, the steam enters into condenser and reaches the deaerator chamber. At deaerator, the unwanted gases are removed. The condensed water again reaches preheated chamber, thus completing the loop. As described before, the various input parameters used in our modelling study are presented in Table 1.

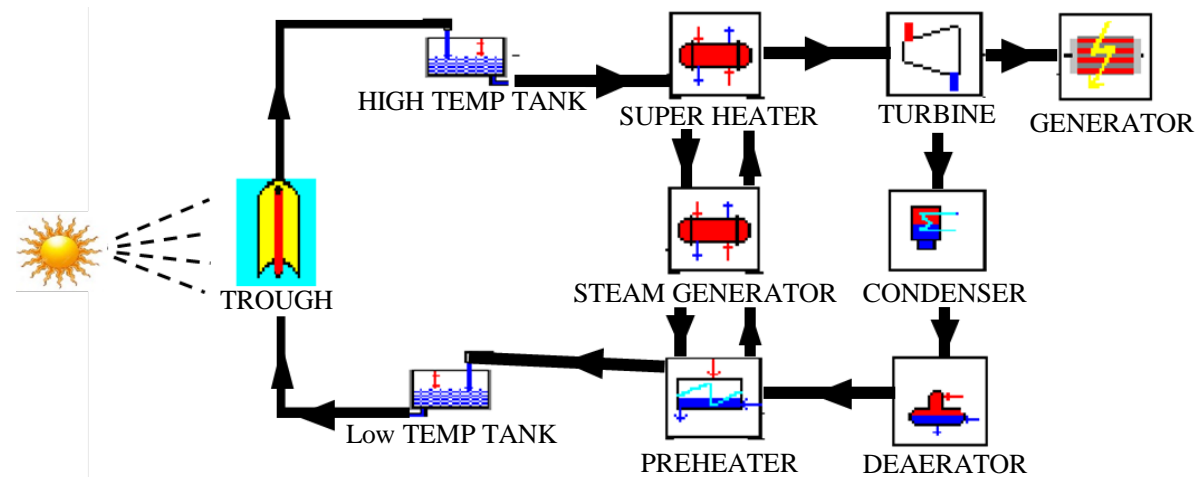

Figure 2. Schematic diagram showing the different components used in modelling studies of our study. In this diagram, the two types of fluids circulated in a closed loop. On the left hand part of the figure, therminol fluid passes through the trough, high temperature tank super heater preheat followed by low temperature tank and finally reaches to PTC again; on right hand side of figure, the water gets preheated enters into steam generator super heater and then the turbine condenser deaerator, from which it enters the preheater again. 


\section{Results}

\subsection{Comparison of 1 MW Solar Thermal Plant}

In Figure 3, the results derived from modelling studies have been presented. The energy generation showed large variation in different months. Additionally, there is zero potential during the months of January, November and December. The annual generation is 3897 MWh. If we compare our results with the installed plant near Delhi the annual electricity generation is nearly 2.85 times the actual generation (1365 MWh/annum). Additionally it is reported that the plant remain non-operational during the months of January, July, August, December [10]. Thus our simulation results are calibrated with the installed plant near Delhi.

\subsection{Solar Thermal Power Map of India}

Now, it is interesting to study the energy generation if Gurgaon $1 \mathrm{MW}$ capacity plant has been constructed at various locations in different parts of India. For this purpose, $1^{\circ} \times 1^{\circ}$ grid spacing with a total of 296 locations has been identified (Figure 4(a)). Similarly detailed maps for two states, namely Gujarat in the western part of India and Tamil Nadu in the southern part of India have also been considered. In these two states, we have

\section{Table 1. Input and initial parameters of solar thermal power plant.}

\begin{tabular}{|c|c|c|}
\hline S. No & Equipment & Input and initial parameters \\
\hline 1 & PTC Field & $\begin{array}{l}\text { For example, length of Solar Collector Assembly (SCA): } 120 \mathrm{~m} \text {, row spacing }=12.5 \mathrm{~m} \text {, } \\
\text { inlet temperature }=227^{\circ} \mathrm{C} \text {, DNI }=2160 \mathrm{KJ} / \mathrm{hr} \cdot \mathrm{m}^{2} \text {, Ambient Temperature }=23^{\circ} \mathrm{C} \text {, loss } \\
\text { coefficient parameter: } \mathrm{A}=73.6, \mathrm{~B}=0.0042, \mathrm{C}=7.40\end{array}$ \\
\hline 2 & Turbine & Mechanical efficiency $=0.99$ \\
\hline 3 & High temperature tank & $\begin{array}{l}\text { Volume }=20 \mathrm{~m}^{3} \text {, maximum level }=18 \mathrm{~m}^{3} \text {, minimum level }=5 \mathrm{~m}^{3} \text {, dry loss co-efficient: } 4 \\
\mathrm{KJ} / \mathrm{hr} \cdot \mathrm{m}^{2} \cdot \mathrm{K}\end{array}$ \\
\hline 4 & Low temperature tank & $\begin{array}{l}\text { Volume }=20 \mathrm{~m}^{3} \text {, maximum level }=18 \mathrm{~m}^{3} \text {, minimum level }=5 \mathrm{~m}^{3} \text {, dry loss co-efficient: } 4 \\
\mathrm{KJ} / \mathrm{hr} \cdot \mathrm{m}^{2} \cdot \mathrm{K}\end{array}$ \\
\hline 5 & Super heater & Heat exchanger type: rankine cycle, input temperature $=390^{\circ} \mathrm{C}$ \\
\hline 6 & Steam generator & Heat exchanger type: rankine cycle, input temperature $=260^{\circ} \mathrm{C}$ \\
\hline 7 & Preheater & Heat exchanger type: rankine cycle, input temperature $=105^{\circ} \mathrm{C}$ \\
\hline
\end{tabular}

Simulated annual power:1736 MWh

Actual generation of the Gurgaon plant:1365 MWh

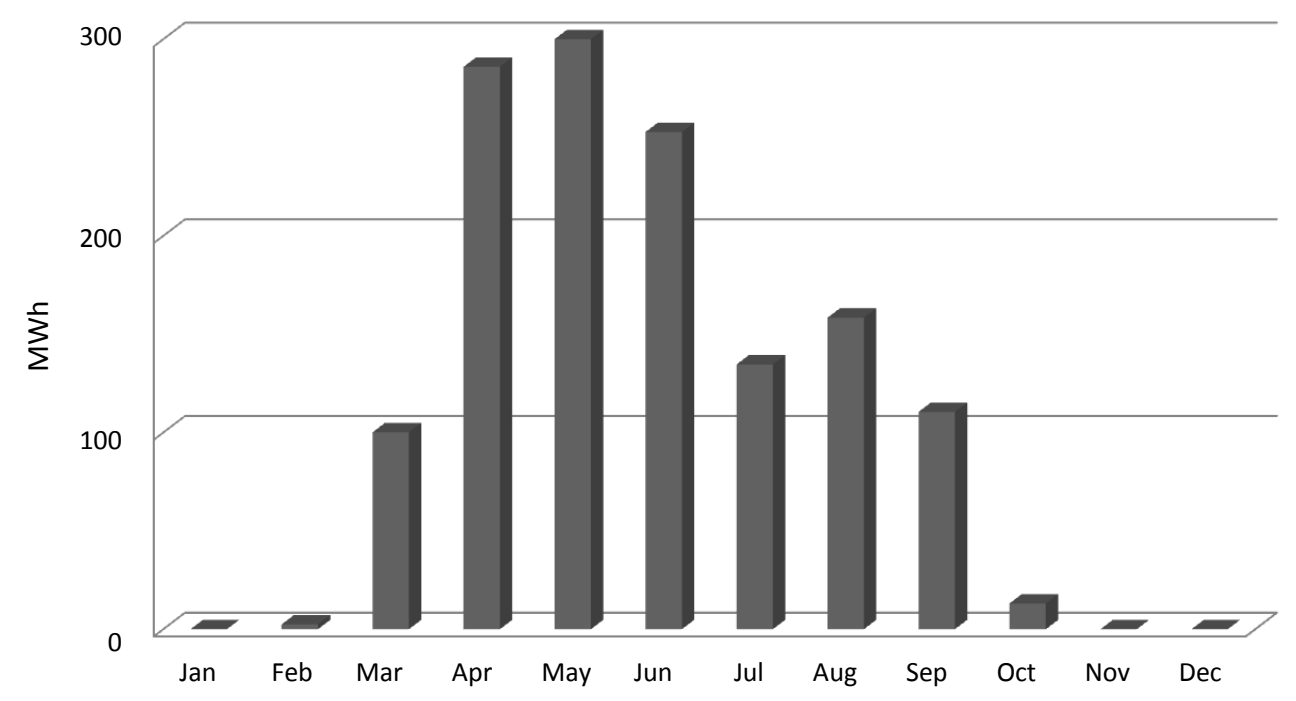

Figure 3. Our present modelling results normalized to $1 \mathrm{MW}$ power plant and the power generation of the installed solar thermal power plant at Gurgaon, Delhi. Less than 5\% match is achieved for most of the monthly generation data. 

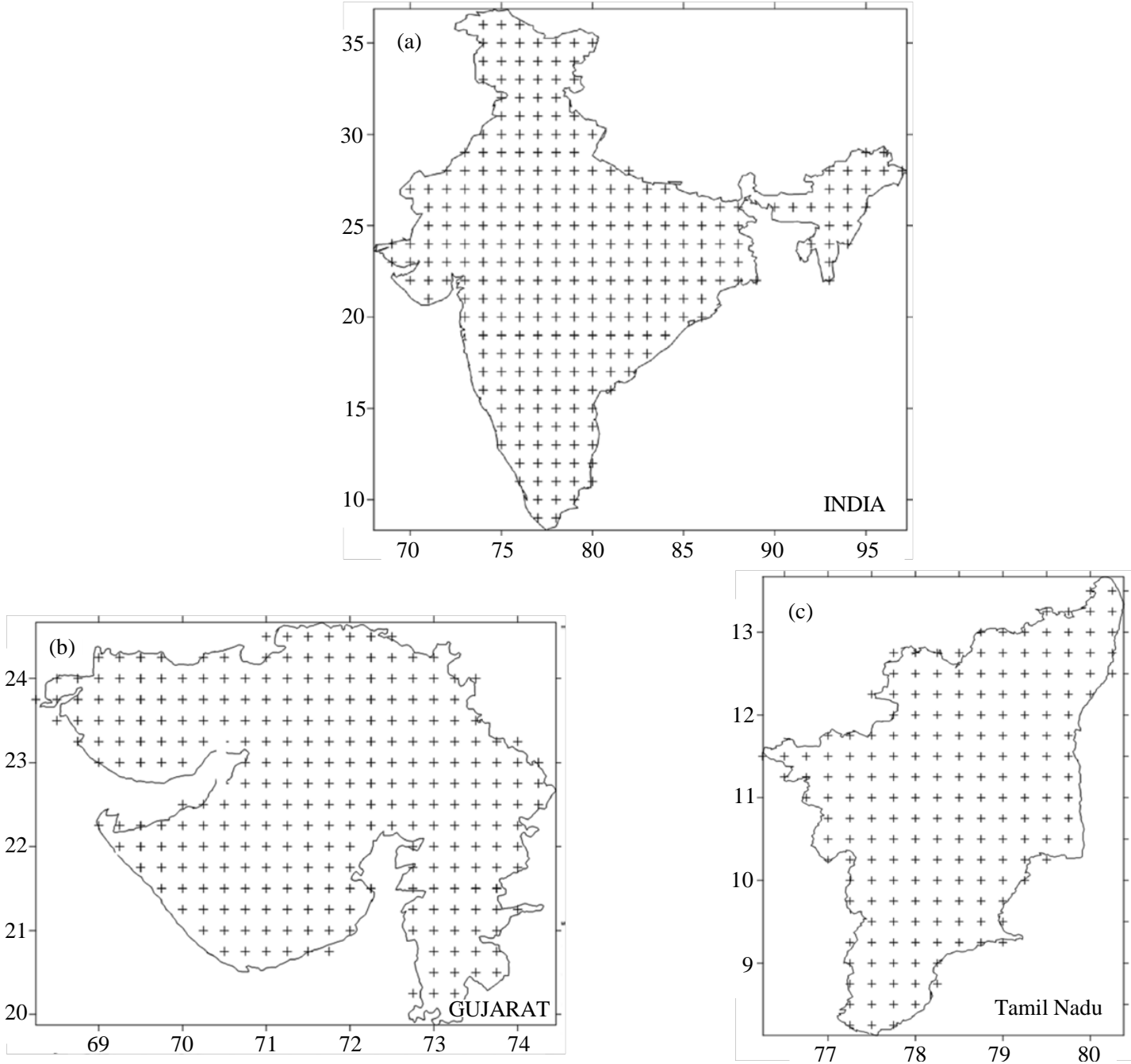

Figure 4. Different locations considered for our modelling studies. $1^{\circ} \times 1^{\circ}$ locations are considered for India. A total of 296 number of locations are shown with + symbol in (a). In (b) and (c) location map for Gujarat and Tamil Nadu states are shown for both the states. $0.25^{\circ} \times 0.25^{\circ}$ spacing is considered as can be seen in the figure.

considered $0.25^{\circ} \times 0.25^{\circ}$ (Figure 4(b) and Figure 4(c)). A total of 273 number of locations for Gujarat state and 197 number of locations for Tamil Nadu state have been considered. The closer station spacing helped to generate more detailed power generation maps for the two states. The simulation studies are continued at all these locations. At each location, latitude and longitude values are fed to the Meteonorm software and DNI, average temperature, wind speed, wind direction etc, parameters have been obtained. These parameters are fed to the TRNSYS software and the solar thermal energy generation averaged month wise are computed.

After getting the solar thermal energy generation for all the locations contouring have been carried out by gridding using Surfer software version 11 [14]. After getting the generation values at all the locations for all months, total value for the whole year has been computed and presented in Figure 5. As can be seen from the figure a large variation of $600 \mathrm{MWH}$ to nearly $2600 \mathrm{MWH}$ per annum is possible in India for $1 \mathrm{MW}$ power plant using parabolic trough technology. It may be noted that we have first simulated power generation and calibrated with the plant near Delhi. As can be seen southern states like Tamil Nadu, Kerala, Karnataka, southern part of Andhra Pradesh and eastern part of Maharashtra and parts of Madhya Pradesh, Gujarat and southern parts of Rajasthan seems to be having higher potential as compared to other states. All the states of north eastern region have less than $1400 \mathrm{MWh} / \mathrm{annum}$ potential as compared to 1800 to $2600 \mathrm{MWh} / \mathrm{annum}$ for the southern states. While such is the case, majority of the northern states like Jammu and Kashmir, Punjab, Uttar Pradesh, Bihar, 


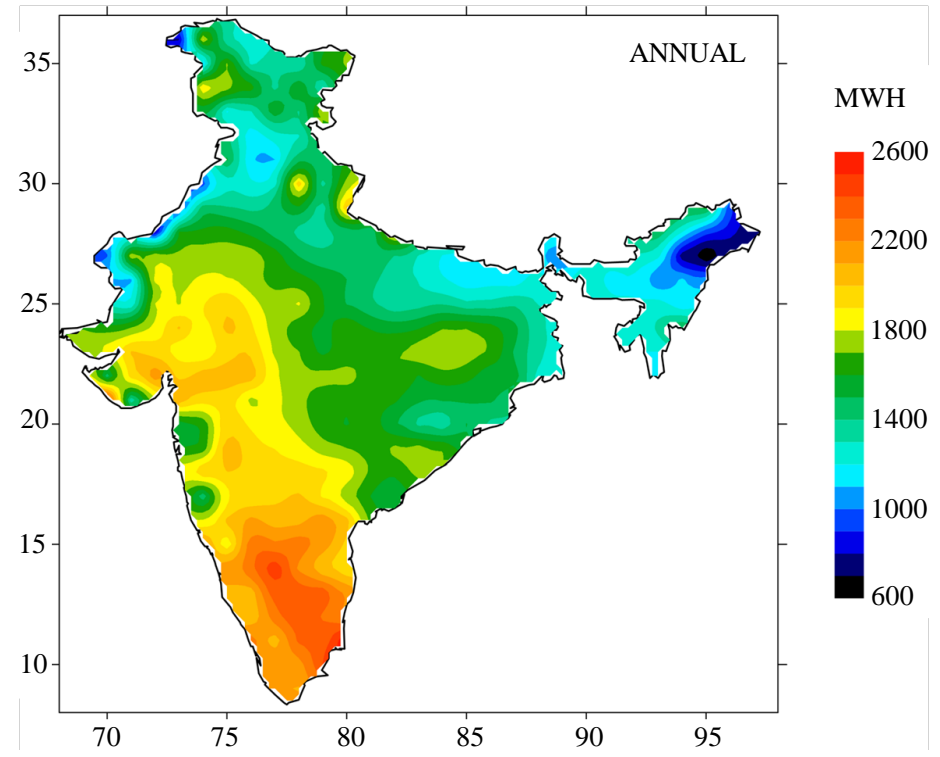

Figure 5. Solar thermal energy generation potential map for India using PTC technology. Considering 1 MW power plant at different locations. The solar thermal potential ranges from $600 \mathrm{MWh} /$ annum in parts of north eastern region to about 2600 MWh/annum in parts of south India.

West Bengal eastern part of Orissa etc, are having medium range of potential with an annual energy potential of about 1000 to $1800 \mathrm{MWh} /$ annum as shown in Figure 5.

The solar thermal energy generation potential for different months from January to December has been presented in Figure 6. As can be seen from the figure, during the months of January, November and December the solar thermal energy potential is near zero for most of the northern part, eastern part and north eastern parts of India. Southern states always have nearly good potential on all the months. For example, in Tamil Nadu, Kerala, Karnataka and Andhra Pradesh during June and July, the potential varies from 30 to $100 \mathrm{MWh}$ as compared to other months as shown in Figure 10.

\subsection{Gujarat Solar Thermal Power Map}

Figure 7 shows the annual energy generation potential for Gujarat state. The energy potential varies from 1600 to $2300 \mathrm{MWh} /$ annum. Interestingly, major part of Saurashtra region and middle part of southern Gujarat have shown higher potential as compared to other regions.

The energy generation month wise are presented except for the month of December (Figure 8). Due to low temperature in December the energy generation potential is near zero. As can be seen, during the months of January, February, March, April, May, October, November and December, Kutch region has exhibited low thermal potential as compared to other regions.

From Figure 9, we have further analyzed the weather parameters for the month of April for Gujarat state. The parameters considered are the DNI values in Watts/Sq. m, wind speed in $\mathrm{m} / \mathrm{s}$ and temperature in ${ }^{\circ} \mathrm{C}$. It can be seen from these parameters that the solar radiation for the month of April in Kutch region is the lowest as compared to the rest of Gujarat as shown in Figure 9(a). The wind speed is maximum towards northern part of Saurashtra as compared to rest of the state as shown in Figure 9(b). The average ambient temperature in the northern part of Gujarat covering Ahmedabad Gandhinagar, Patan, etc. districts have shown more than $31^{\circ} \mathrm{C}$ temperature as shown in Figure 9(c). Accordingly, radiation (DNI) parameter plays a dominant role in solar thermal as compared to other parameters namely, the wind speed and ambient temperature.

\subsection{Tamil Nadu Solar Thermal Power Map}

We can see the annual energy generation for Tamil Nadu state in Figure 10. The annual energy ranges from 1850 to 2650 MWh. In Tamil Nadu region, western half of Tamil Nadu has better potential as compared to eastern half of the state. 

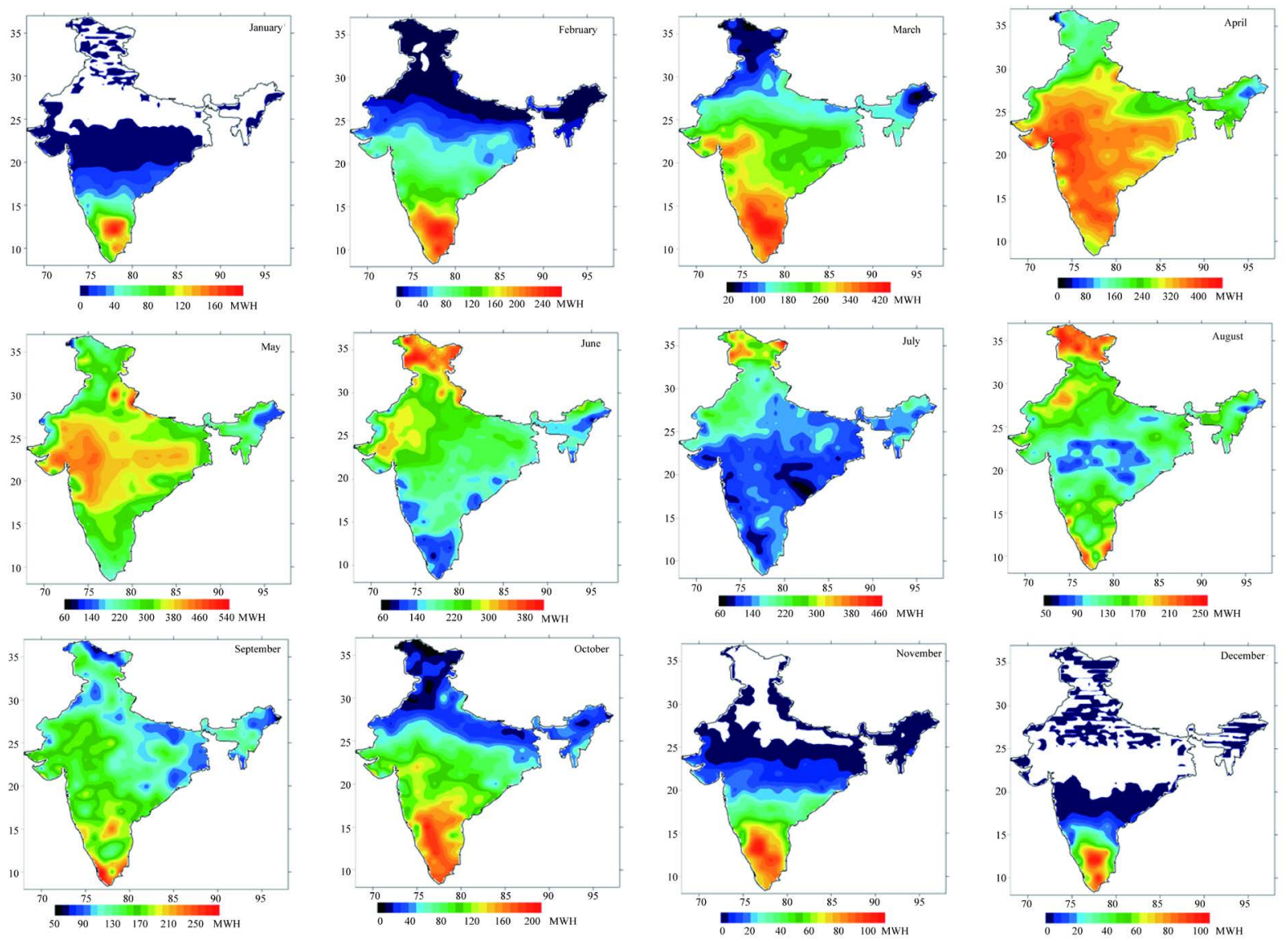

Figure 6. Solar thermal energy potential for different months in India for $1 \mathrm{MW}$ power plant near zero potential for the months of January, November, December in most of the north Indian states may be observed on the other hand more potential has been observed in Sothern states namely Tamil Nadu, Kerala, Karnataka and southern part of Andhra Pradesh.

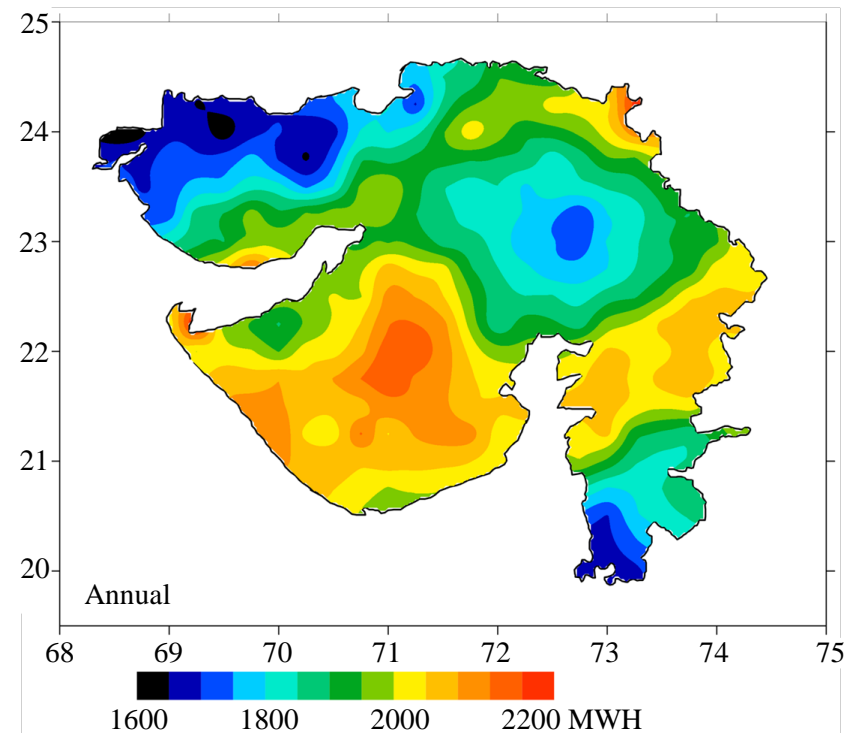

Figure 7. Solar thermal energy potential for $1 \mathrm{MW}$ for Gujarat state poor potential near Kutch and southern part of south Gujarat and north eastern part of Gujarat may be observed. On the other hand, large part of Saurashtra region and middle part of south Gujarat have shown greater potential. The annual potential ranges from 1600 to nearly 2300 MWh. 

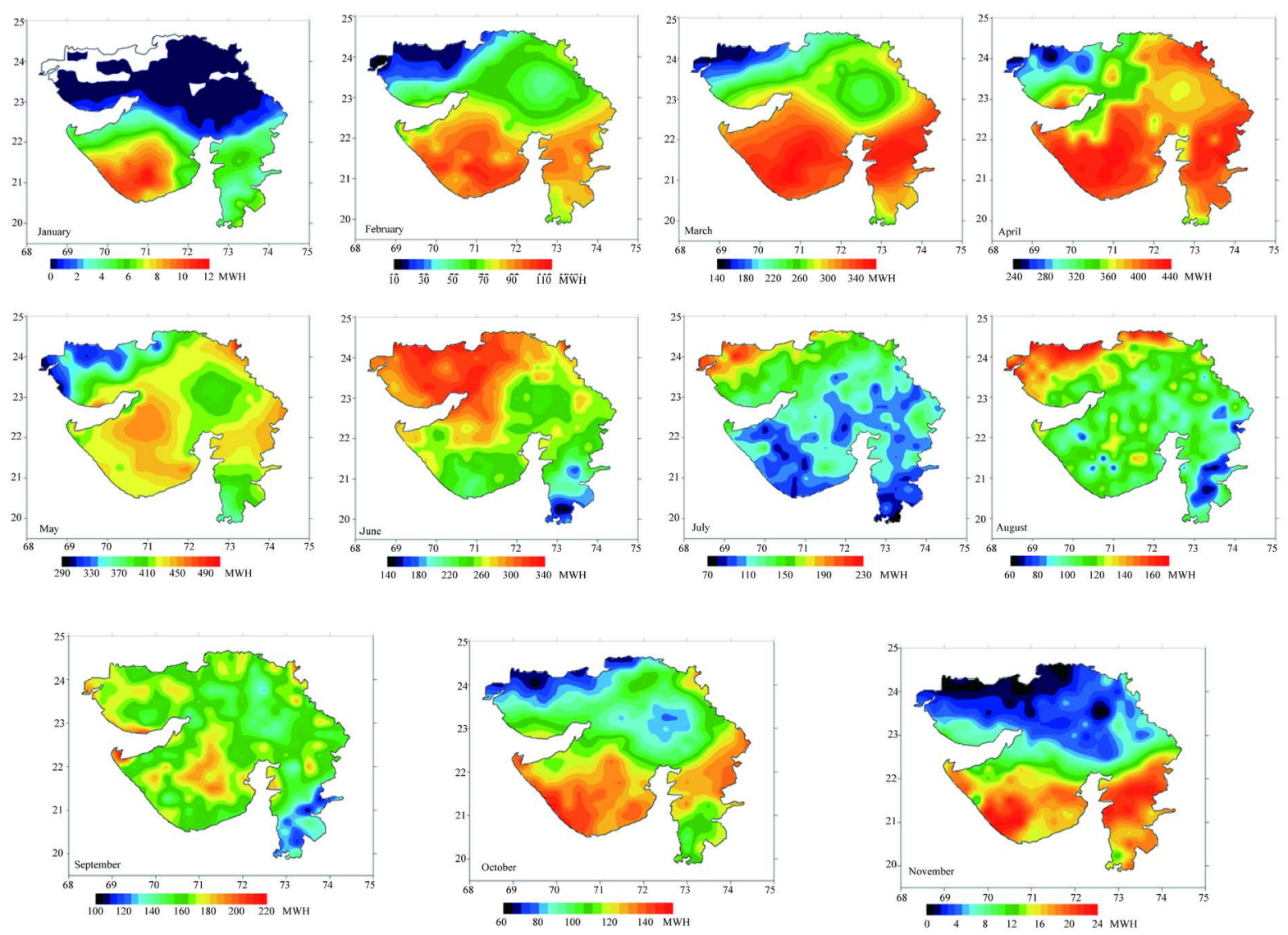

Figure 8. Solar thermal energy potential for different months of Gujarat state near zero potential during the months of January, October and November months near the Kutch and surrounding regions can be seen. Due to near zero potential in all parts of Gujarat, the $1 \mathrm{MW}$ power plant may become non-operational in Gujarat.

The energy generation for all the 12 months for Tamil Nadu state can be seen in Figure 11. During January and December months, the maximum potential range is about 125 to $190 \mathrm{MWh}$. Maximum potential is observed during the months of March and April, where the energy generation reaches to more than $400 \mathrm{MWh}$.

\section{Discussion}

It is estimated that by the year 2030 the electricity generation from solar energy will be dominating as compared to other source of energy [15]. In recent years, the cost of solar photo voltaic has fallen to 50\% less as compared to the prices of 2000 . It is expected that cost may still goes down by $20 \%$ to $25 \%$ due to various innovations in solar technology. While the entire nation is facing the power shortage, Gujarat state has $3000 \mathrm{MW}$ more power than its requirement. Additionally, during 2012 Gujarat alone has crossed 600 MW power through solar while rest of the country could produce only about $200 \mathrm{MW}$. Gujarat is going ahead using solar power with innovative concepts. For example the capital city of Gujarat-Gandhinagar, the rooftop solar has been initiated. Similarly solar panels have been installed over a canal on experimental basis with 1 MW capacity. Realizing the success story of canal top project, it has further extended to $10 \mathrm{MW}$ near Baroda. In another innovation through modelling studies, it is proposed that solar panels can be installed over agricultural lands also by putting up the solar panels in a chess board like pattern. The main advantage of this concept is the dual usage of the land. The farmer can continue farming with different crops, while on top of it power can be generated for his and his village use [16]. Recognizing the importance of this concept, government of Gujarat has initiated a major project to put up solar panels at 4 different agricultural farms and to study the shadow effect on different crops. The project is presently being worked out by government of Gujarat in close association with different agricultural universities. Due to recent realization of climate change problem more stress is being given to renewable energy production [17] [18]. 

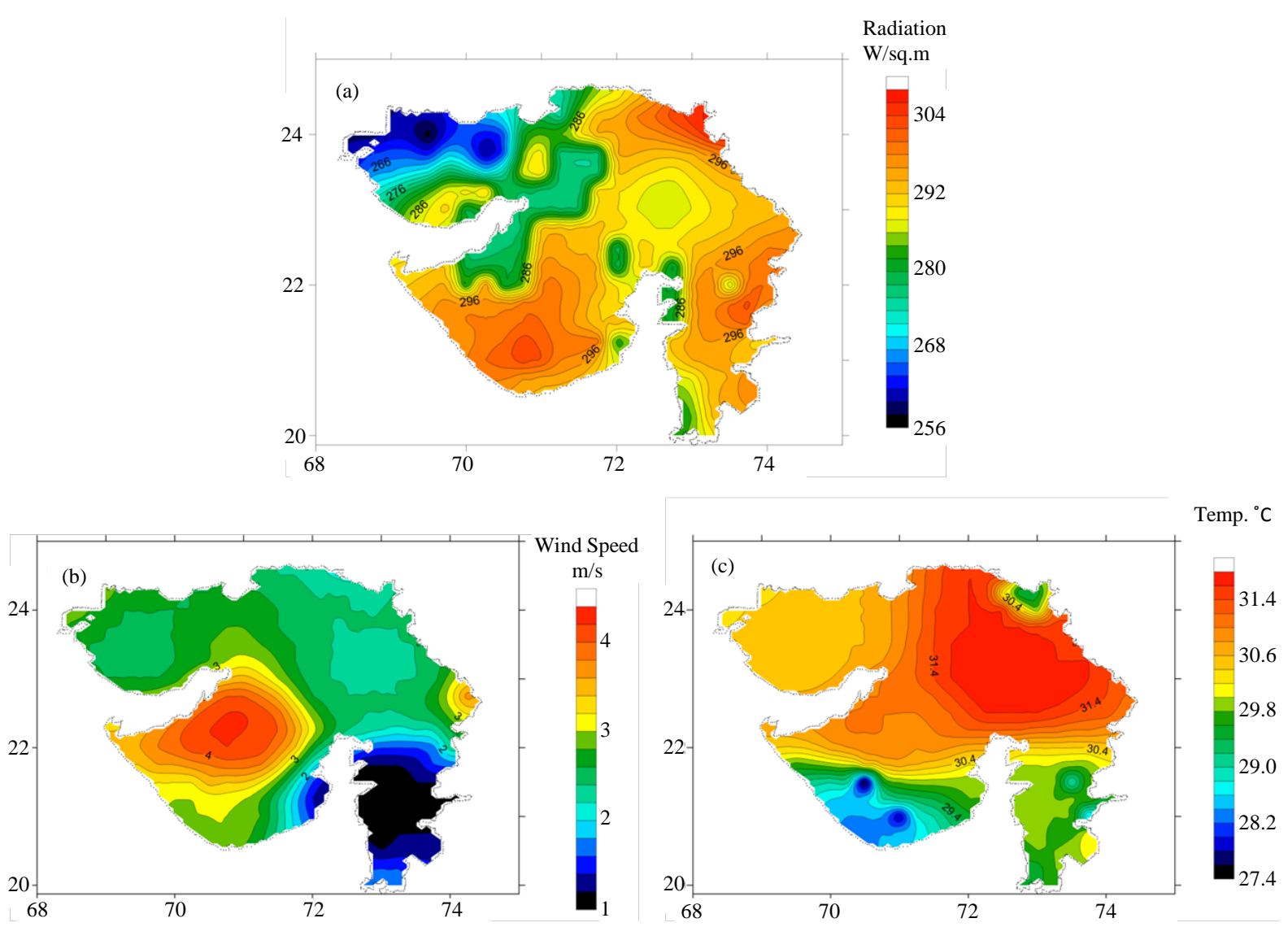

Figure 9. The radiation, the wind speed and the temperature distribution for Gujarat state during the month of April, can be seen that a poor radiation in Kutch region compared to other parts of the state.

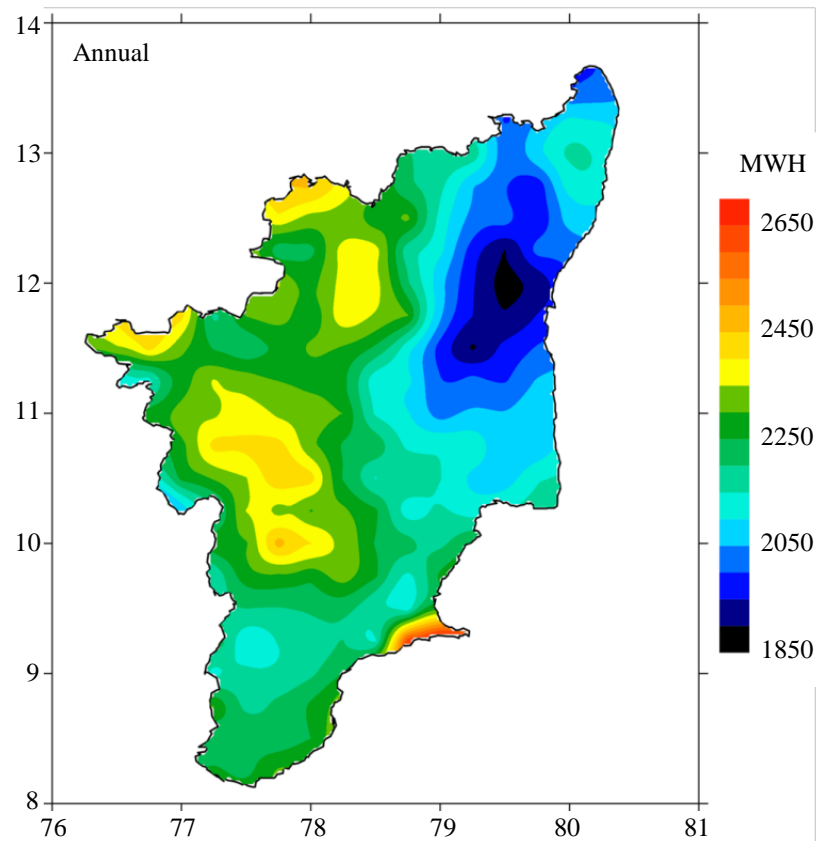

Figure 10. Solar thermal energy potential for Tamil Nadu state for $1 \mathrm{MW}$ power plant the minimum annual energy potential is about 1850 MWh and reaches 2650 MWh. Western part of Tamil Nadu has greater potential as compared to eastern and southern part of the region. 

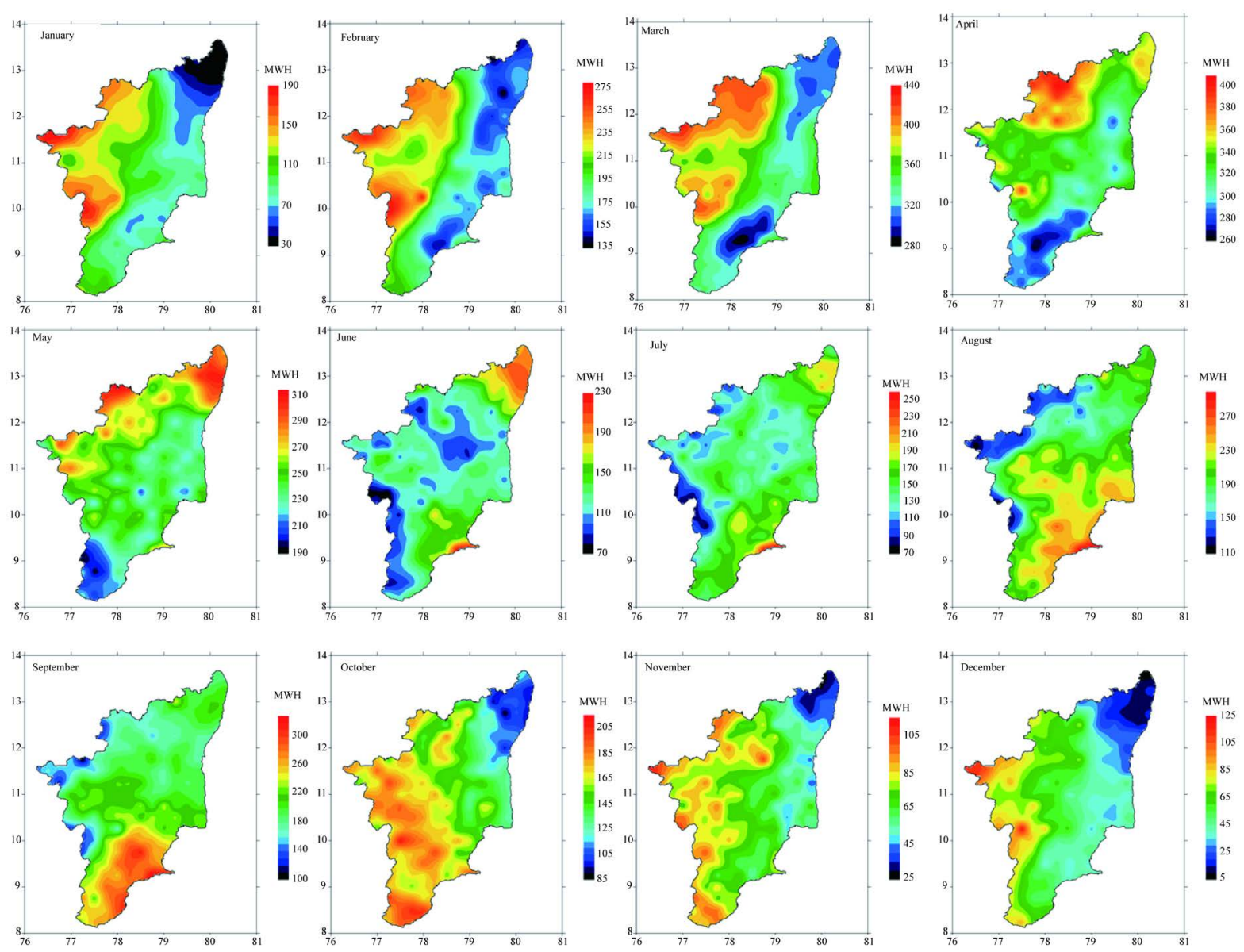

Figure 11. Solar thermal energy potential for $1 \mathrm{MW}$ power plant in different months. During all the months, the potential reaches to about $100 \mathrm{MWh}$.

A comparative study has been made between solar thermal energy generation potential and solar PV potential for India and also for Gujarat state and shown in Figure 12. It may be noted that both of them are based on modelling studies using different strategies. Solar thermal energy potential has been estimated by simulating the technology used in the solar thermal power plant of $1 \mathrm{MW}$ capacity at Gurgaon near Delhi, whereas solar PV potential has been estimated considering the solar panels kept in 1 acre of land. However, the two maps can be compared by considering the low and high potential. Interestingly both the solar PV and solar thermal technology have shown poor estimation towards eastern and north eastern parts of India. The southern part of India seems to have large potential for both the technologies. Similarly, from Figure 12(c) and Figure 12(d) one can compare the annual energy generation using both the technologies for Gujarat state. Northern and western parts of the Kutch region has shown poor potential and southern part of Saurashtra and middle part of southern Gujarat have shown good potential for both the technologies.

\section{Conclusion}

The present research study is based on the preparation of Solar thermal energy potential map for India on a regional scale with $1^{\circ} \times 1^{\circ}$ spacing and more detailed spacing of $0.25^{\circ} \times 0.25^{\circ}$ for Gujarat and Tamil Nadu states. We have simulated a solar thermal plant and compared with the installed solar thermal plant of 1 MW capacity at Gurgaon near New Delhi. This plant has helped to calibrate our results. After calibration, the solar thermal energy generation using PTC technology has been computed for the designed plant at different location points of India in a gridded fashion. Large potential is observed at most of the southern states and medium to poor potential is observed for most of the northern and north eastern states of India. Our map will be useful to all the solar energy developing industries and also to decision makers in choosing the location for possible installation of 

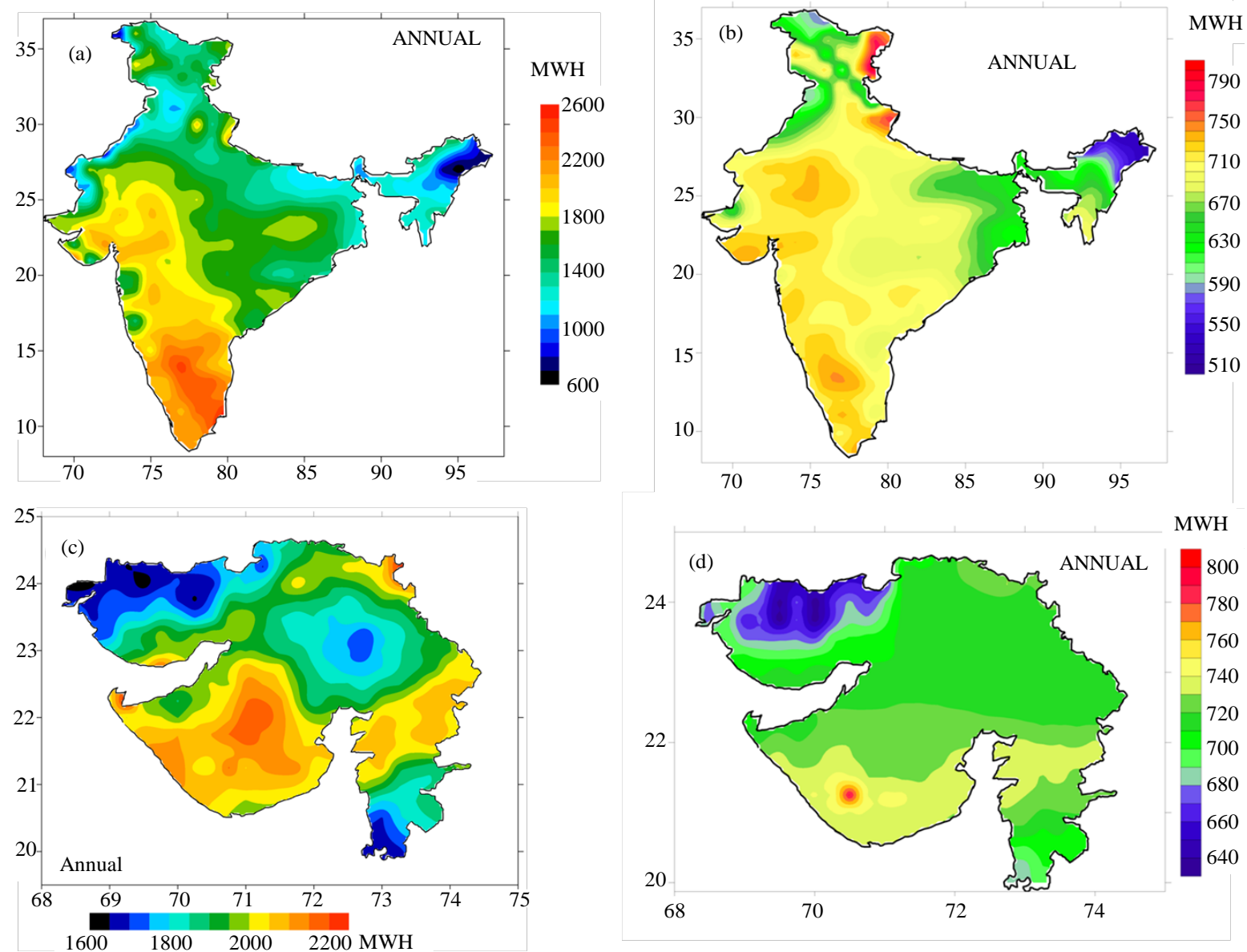

Figure 12. Comparison of solar thermal energy for $1 \mathrm{MW}$ power plant (a) and solar PV potential in 1 acre of land (b). Western and southern parts of India have exhibited large potential for both solar PV and solar thermal energy generation. Medium and low potential can be seen in both the maps for eastern and north eastern parts of India ((a) and (b)). Similarly northern part of Kutch region seems to be having poor potential for both solar PV and solar thermal generation. As can be seen in solar thermal map (c) and solar PV map (d). Relatively large potential in southern part of Saurashtra and middle part of south Gujarat.

large scale solar thermal parks. This greatly helps in reducing the cost. For example, if Rs. 8 to 10 crores are spent to install $1 \mathrm{MW}$ solar thermal power plant in large potential region of Tamil Nadu, it may cost nearly double to establish a solar plant if one aims to produce same amount of annual generation. This is because, annual energy generation in western part of Tamil Nadu state is more than 1800 MWh for $1 \mathrm{MW}$ plant and for the same plant in NE states it is less than half. Thus, our study directly helps the decision makers and planners to choose the optimal location such that one can generate more energy with less cost.

\section{Acknowledgements}

We are thankful to VCMT, Sri DJ Pandian, IAS and MD, GSPC Sri Atanu Chakraborthy, IAS for all the encouragement. We wish to thank all the GERMI staff for giving full support. Help rendered by Dr. Sagar Kumar Agaravat, Scientist, GERMI and Sri Jaymin Gajjar, Research Associate, GERMI is gratefully acknowledged. Special thanks goes to Prasanth Gopiyani, the summer internship coordinator during execution of the project.

\section{References}

[1] Löschel, A. Moslener, U. and Rübbelke, D.T. (2010) Indicators of Energy Security in Industrialised Countries. Energy Policy, 38, 1665-1671. http://www.sciencedirect.com/science/article/pii/S0301421509002262 http://dx.doi.org/10.1016/j.enpol.2009.03.061 
[2] Vivoda, V. (2010) Evaluating Energy Security in the Asia-Pacific Region: A Novel Methodological Approach. Energy Policy, 38, 5258-5263. http://www.sciencedirect.com/science/article/pii/S030142151000399X http://dx.doi.org/10.1016/j.enpol.2010.05.028

[3] Winzer, C. (2012) Conceptualizing Energy Security. Energy Policy, 46, 36-48. http://www.sciencedirect.com/science/article/pii/S0301421512002029 http://dx.doi.org/10.1016/j.enpol.2012.02.067

[4] Bohi, D.R. and Toman, M.A. (1993) Energy Security: Externalities and Policies. Energy Policy, 21, $1093-1109$. http://www.sciencedirect.com/science/article/pii/030142159390260M http://dx.doi.org/10.1016/0301-4215(93)90260-M

[5] Cherp, A. and Jewell, J. (2011) The Three Perspectives on Energy Security: Intellectual History, Disciplinary Roots and the Potential for Integration. Current Opinion in Environmental Sustainability, 3, 202-212. http://www.sciencedirect.com/science/article/pii/S1877343511000583 http://dx.doi.org/10.1016/j.cosust.2011.07.001

[6] Lal, S. and Raturi, A. (2012) Techno-Economic Analysis of a Hybrid Mini-Grid System for Fiji Islands. International Journal of Energy and Environmental Engineering, 3, 10. http://dx.doi.org/10.1186/2251-6832-3-10

[7] Harinarayana, T. and Kashyap, K.J. (2014) Solar Energy Generation Potential Estimation in India and Gujarat, Andhra, Telangana States. Smart Grid and Renewable Energy, 5, 275. http://file.scirp.org/Html/2-6401360 51455.htm

[8] Guerrero-Lemus, R. and Martínez-Duart, J.M. (2013) Concentrated Solar Power. Renewable Energies and $\mathrm{CO}_{2}$, 3, 135-151. http://link.springer.com/chapter/10.1007/978-1-4471-4385-7_7

[9] Yari, M. (2009) Performance Analysis of the Different Organic Rankine Cycles (ORCs) Using Dry Fluids. International Journal of Exergy, 6, 323-342. http://www.inderscienceonline.com/doi/abs/10.1504/IJEX.2009.025324 http://dx.doi.org/10.1504/ijex.2009.025324

[10] Desai, N.B., Bandyopadhyay, S. Nayak, J.K., Banerjee, R. and Kedare, S.B. (2014) Simulation of 1 MWe Solar Thermal Power Plant. Energy Procedia, 57, 507-516. http://www.sciencedirect.com/science/article/pii/S1876610214015719 http://dx.doi.org/10.1016/j.egypro.2014.10.204

[11] Günther, M. Joemann, M. Csambor, S. Guizani, A. Krüger, D. and Hirsch, T. (2011) Parabolic Trough Technology, Advanced CST Teaching Materials. enerMENA, Chapter 5. http://goo.gl/VWBwUB

[12] Meteonorm v7.1.5. http://www.meteotest.ch/en/footernavi/solar_energy/meteonorm http://meteonorm.com

[13] TRNSYS v17.2.4. http://sel.me.wisc.edu/trnsys http://www.trnsys.com

[14] Surfer v11. http://downloads.goldensoftware.com/guides/Surfer11TrainingGuide.pdf http://www.goldensoftware.com/products/surfer

[15] European Photovoltaic Industry Association (2014) Global Market Outlook for Photovoltaics. http://www.epia.org/news/publications/

[16] Harinarayana, T. and Vasavi, K.S.V. (2014) Solar Energy Generation Using Agriculture Cultivated Lands. Smart Grid and Renewable Energy. http://file.scirp.org/Html/2-6401313 42763.htm

[17] Dincer, I. (2000) Renewable Energy and Sustainable Development: A Crucial Review. Renewable and Sustainable Energy Reviews, 4, 157-175. http://www.sciencedirect.com/science/article/pii/S1364032199000118 http://dx.doi.org/10.1016/s1364-0321(99)00011-8

[18] Boyle, G. (2004) Renewable Energy, Oxford University Press, Oxford. 